\section{A novel method to insert drain atraumatically after liposuction in gynaecomastia}

\section{Sir,}

Gynaecomastia is a complex benign condition characterised by enlargement of male breasts affecting mainly the young population. It can be caused by hypertrophy of the ductal tissue, stroma and/or fat. Surgery remains the mainstay of the management. It can be managed by direct excision, liposuction, combination of direct excision and liposuction. ${ }^{[1]}$ According to the literature, the overall complication rate for gynaecomastia surgery is $15.5 \%$ with the highest rate in Grade 1 patients. ${ }^{[2]}$ The reported complications are seroma, minor bleeding, skin dehiscence, wound

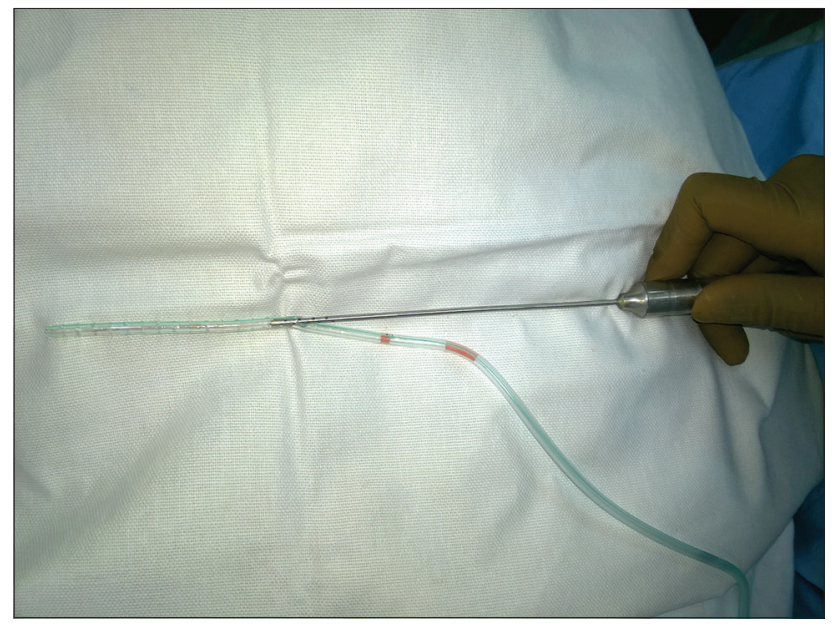

Figure 1: With the help of a No. 11 blade make a slit on the surface of the drain going to be inserted. Insert the infiltration cannula used for tumeuscent infiltration into the slit and advance infection and haematoma necessitating evacuation in operation theatre. Drain placement is routine after liposuction of severe gynaecomastia. This is achieved blindly and forcefully with the help of an artery forceps. This may cause injury to the skin or underlying muscle.

The famous surgeon, Illouz, published his ten commandments for liposuction in 1989..$^{31}$ The pertinent points were (1) surgeon should use only small blunt cannulas and (2) the technique demands blind surgery which reiterates the experience surgeon should have. Inspired from these principles we developed an atraumatic method to insert the drain after the liposuction. The steps are as follows:

- Step 1 [Figure 1] - Take a fine blunt infiltration cannula and the drain going to be inserted

- Step 2 [Figure 1] - Make a hole on the surface of drain tube with the help of No. 11 blade

- Step 3 [Figure 2] - Insert the infiltrating cannula into the drain tube

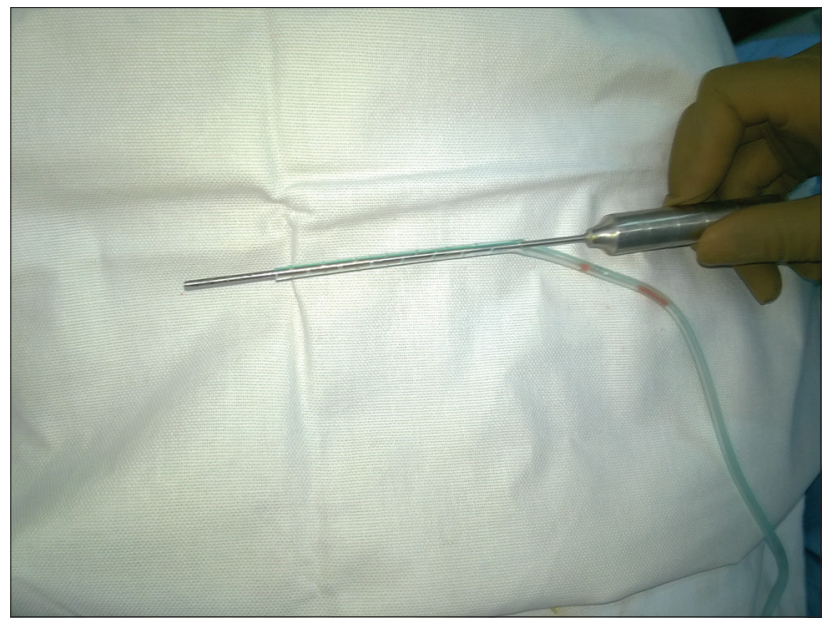

Figure 2: After advancing the infiltration cannula through the drain 


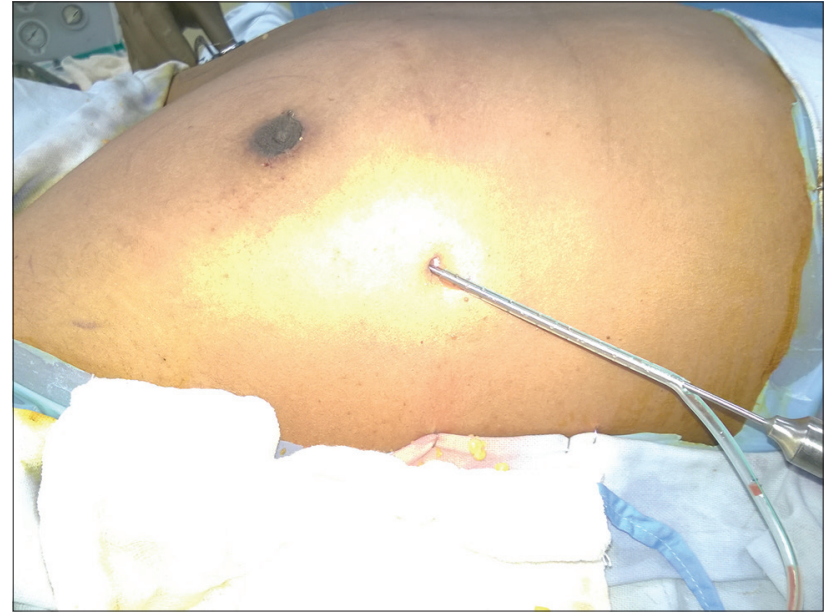

Figure 3: Use the same port through which infiltration had been done. Insert the infiltration cannula which carries the drain

- Step 4 [Figures 3 and 4$]$-Use the port used for infiltration again to insert the drain with the help of infiltrating cannula. Cannula being blunt there is no risk of injury while inserting. Remove the infiltrating cannula leaving the drain. Drain can be removed after 24-48 h.

\section{Financial support and sponsorship}

Nil.

\section{Conflicts of interest}

There are no conflicts of interest.

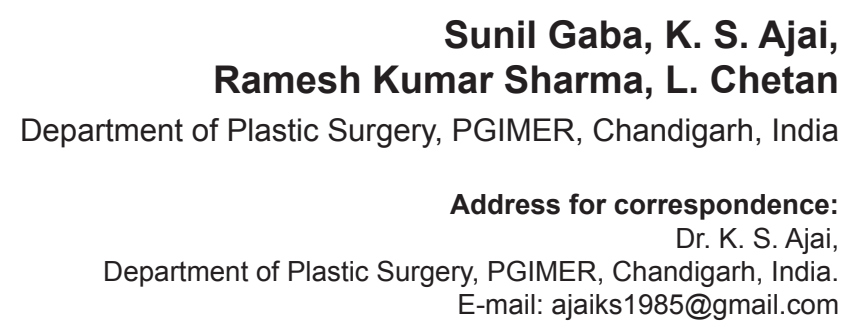

\section{REFERENCES}

1. Arvind A, Khan MA, Srinivasan K, Roberts J. Gynaecomastia

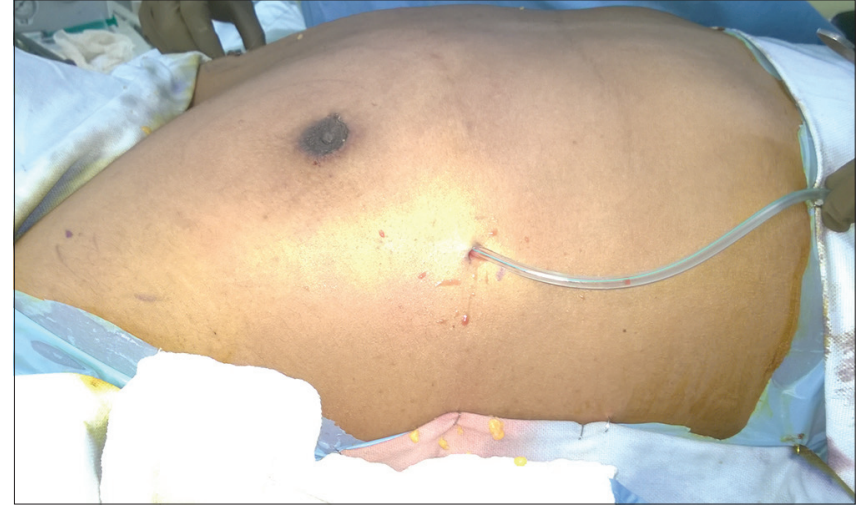

Figure 4: Withdraw the infiltration cannula. Hold the drain part at the entry site so that drain stays in the same position, and fix the drain

correction: A review of our experience. Indian J Plast Surg 2014;47:56-60.

2. Colombo-Benkmann M, Buse B, Stern J, Herfarth C. Indications for and results of surgical therapy for male gynecomastia. Am J Surg 1999;178:60-3.

3. Khanna A, Filobbos G. Avoiding unfavourable outcomes in liposuction. Indian J Plast Surg 2013;46:393-400.

This is an open access journal, and articles are distributed under the terms of the Creative Commons Attribution-NonCommercial-ShareAlike 4.0 License, which allows others to remix, tweak, and build upon the work non-commercially, as long as appropriate credit is given and the new creations are licensed under the identical terms.

\begin{tabular}{|l|l|}
\hline \multicolumn{2}{|c|}{ Access this article online } \\
\hline Quick Response Code: & Website: \\
\hline
\end{tabular}

How to cite this article: Gaba S, Ajai KS, Sharma RK, Chetan L. A novel method to insert drain atraumatically after liposuction in gynaecomastia. Indian J Plast Surg 2018;51:102-3.

() 2018 Indian Journal of Plastic Surgery | Published by Wolters Kluwer - Medknow 